\title{
ANALISIS DEFORMASI GUNUNG BROMO AKIBAT AKTIVITAS ERUPSI PADA DESEMBER 2015 - FEBRUARI 2016 MENGGUNAKAN TEKNOLOGI DIFFERENTIAL INTERFEROMETRY SYNTHETIC APERTURE RADAR (DInSAR)
}

\author{
Muhammad Taufik ${ }^{1}$, Imelda Vinny Aprillisa², Ira Mutiara Anjasmara ${ }^{3}$ \\ Departemen Teknik Geomatika, FTSLK-ITS, Kampus ITS Sukolilo, Surabaya, 60111, Indonesia \\ e-mail: ${ }^{2 i m e l d a v i n n y @ y a h o o . c o m ~}$
}

\begin{abstract}
Abstrak
Gunung Bromo merupakan salah satu gunung berapi yang paling aktif di Jawa Timur. Pada Desember 2015 - Januari 2016 Pusat Vulkanologi dan Mitigasi Bencana Geologi mendeteksi adanya peningkatan aktivitas di Gunung Bromo. Aktivitas vulkanik menyebabkan adanya perubahan (deformasi) di wilayah permukaan Gunung Bromo. Deformasi yang ada di permukaan Gunung Bromo dapat diukur dengan berbagai teknologi, salah satunya yaitu menggunakan teknologi Differential Interferometry Synthetic Aperture Radar (DInSAR). Dalam penelitian ini pengukuran deformasi pada permukaan Gunung Bromo dilakukan pengolahan dengan teknologi DInSAR menggunakan metode two-pass dari lima buah citra satelit Sentinel-1A bulan November 2015, Desember 2015, Januari 2016, Februari 2016, dan Maret 2016 serta Digital Elevation Model Shuttle Radar Topography Mission 30 meter. Hasil menunjukkan bahwa metode two-pass teknologi DInSAR dapat merefleksikan peningkatan aktivitas di Gunung Bromo dimana mayoritas deformasi terjadi di kaldera Gunung Bromo. Dari metode ini, nilai Line Of Sight displacement yang dihasilkan menunjukkan bahwa terjadi puncak subsidence pada bulan Desember 2015 - Januari 2016 sebesar -20 mm s/d -60 mm hal ini mengindikasikan jika terjadi peningkatan aktivitas pada kawah Gunung Bromo pada rentang waktu tersebut. Sedangkan puncak uplift terjadi pada bulan Februari 2016 - Maret 2016 sebesar $0 \mathrm{~mm} \mathrm{~s} / \mathrm{d} 40 \mathrm{~mm}$ hal ini mengindikasikan jika aktivitas pada kawah Gunung Bromo sudah mengalami penurunan.
\end{abstract}

Kata kunci : Deformasi, DInSAR, Gunung Bromo, Sentinel-1A

\begin{abstract}
Bromo mountain is one of the most active volcanoes in East Java. In December 2015 - January 2016 the Center for Volcanology and Geological Hazard Mitigation detected increased activities on Bromo mountain. The existence of volcanic activities cause a deformations on the surface of Bromo mountain. The existing deformations on the surface of Mount Bromo can be measured with various technologies such as using DInSAR. In this study, the analysis of deformation on the surface of Mount Bromo are done by DInSAR processing using two-pass method and using five Sentinel-1A satellite imagery in November 2015, December 2015, January 2016, February 2016, and March 2016 and DEM SRTM 30 meters. The results show that the two-pass method of DInSAR can reflect the increased activities in Bromo mountain that cause the deformation of the surface where the majority of deformations occur at the caldera of Bromo mountain. From this method, the result of LOS (Line of Sight) displacement value indicates that the maximum subsidence occured in December 2015 - January 2016 with the value $-20 \mathrm{~mm} \mathrm{~s} / \mathrm{d}-60 \mathrm{~mm}$ it indicates if there were some increased activities on the crater of Bromo mountain in December 2015 to January 2016. While the maximum uplift occurred in February 2016 - March 2016 with the value $0 \mathrm{~mm} \mathrm{~s} / \mathrm{d} 40 \mathrm{~mm}$ it indicates if the activities on the crater of Bromo mountain was decreasing. However, in order validate the accurate value of deformation, it is necessary to compare with other measurements or measuring directly in the field.
\end{abstract}

Keywords : Deformation, DInSAR, Bromo Mountain, Sentinel-1A 


\section{PENDAHULUAN}

Indonesia adalah negara kepulauan yang secara tektonik terletak diantara pertemuan tiga lempeng benua yaitu lempeng Eurasia, lempeng Pasifik, serta lempeng Australia. Interaksi dari ketiga lempeng tersebut menghasilkan deretan pegunungan api (volcanic arc) yang membujur dari selatan hingga timur Indonesia. Terhitung sebanyak 129 buah gunung api aktif berada di Indonesia. Keberadaan gunung api tersebut tentunya memiliki dampak secara langsung terhadap lingkungan, baik itu positif atau negatif. Salah satu dampak negatifnya adalah bahaya letusan gunung api. Letusan gunung api merupakan proses naiknya material magma dari dalam bumi menuju permukaan bumi baik dikeluarkan secara eksplosif maupun efusif (Wismaya dan Anjasmara 2016).

Gunung Bromo merupakan salah satu gunung api yang paling aktif di Jawa Timur. Data menunjukkan, sejak tahun 1804 hingga tahun 2016, Gunung Bromo telah bererupsi lebih dari 50 kali. Aktivitas Gunung Bromo saat ini sebagai aktivitas pasca-kaldera yang ditandai dengan pertumbuhan kerucut lava atau scoria atau cinder cone pada dasar kaldera. Karena posisi dapur magma pasca-kaldera relatif lebih dangkal dengan sistem yang terbuka, maka letusanletusan pasca-kaldera tidak didahului akumulasi energi yang besar sehingga letusannya tergolong letusan kecil. Umumnya letusan yang terjadi adalah letusan eksplosif yang bersifat membangun seperti Stromolian atau Maar. Periode letusan gunung api pasca-kaldera umumnya pendek, rata-rata 10 tahun sekali (Pratomo 2006).

Dengan pendeknya periode letusan dari Gunung Bromo menunjukkan tingginya aktivitas yang terjadi pada dapur magma, hal ini berimplikasi terhadap perubahan bentuk badan atau permukaan berupa mengembang (inflation) dan menyusut (deflation) permukaan gunung tersebut. Perubahan yang signifikan dari gunung api dapat menjadi salah satu indikator akan terjadinya letusan, untuk itu diperlukan pengamatan deformasi dengan melihat perubahan nilai pergeseran permukaan baik dari arah vertikal maupun horizontal. Untuk pengamatan deformasi pada gunung api sendiri ada banyak metode yang dapat dilakukan seperti penggunaan GPS (Global Positioning System), seismometer, dan data survei geofisika lainnya untuk membantu mendeteksi dinamika kegiatan gunung api (Chang-Wook dkk. 2008), selain itu dapat menggunakan teknologi satelit penginderaan jauh aktif yang menyediakan cakupan global untuk pemantauan gunung api (Rivera, Amelung, dan Eco 2016).

\section{Differential Interferometry Synthetic} Aperture Radar (DInSAR) merupakan teknik berbasis radar yang mengekploitasi informasi yang ada pada fase, setidaknya dua citra Synthetic Aperture Radar (SAR) yang diperoleh pada daerah yang sama, pada waktu yang berbeda, untuk memperoleh pengukuran deformasi pada suatu daerah (Hanssen 2001). Penelitian deformasi pada gunung api yang telah dilakukan sebelumnya dengan teknologi Interferometry Synthetic Aperture Radar (InSAR) pada Gunung Merapi (Yudha dkk. 2011). Oleh karena itu pada penelitian ini akan mengolah citra satelit Sentinel-1A dengan menggunakan teknologi Differential Interferometry Synthetic Aperture Radar (DInSAR) untuk mendapatkan besarnya deformasi di Gunung Bromo akibat erupsi pada bulan Desember 2015 Februari 2016.

\section{METODE}

\section{Lokasi Penelitian}

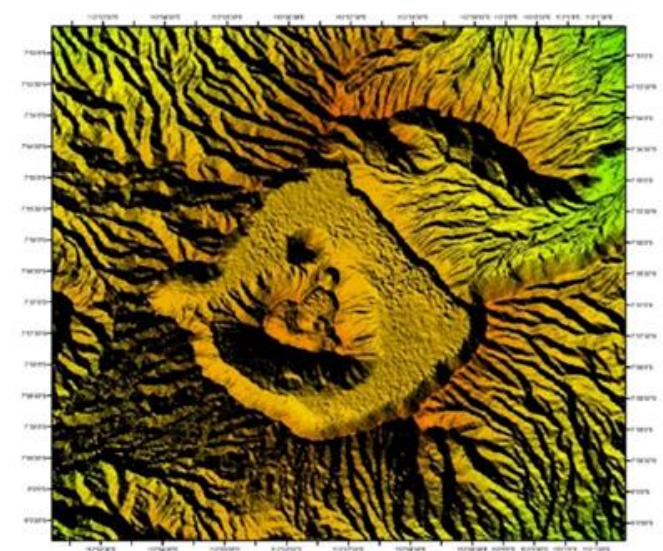

Gambar 1. Lokasi Penelitian Gunung Bromo (USGS 2017)

Lokasi penelitian ini mengambil studi kasus di kawasan Gunung Bromo yang berada di Provinsi Jawa Timur. Pada koordinat $7^{0} 53^{\prime}-8^{0} 0^{\prime} 30^{\prime \prime}$ LS dan $112^{\circ} 53^{\prime} 50^{\prime \prime}-113^{\circ} 1^{\prime} 3^{\circ}$ BT. Gunung bromo dikelilingi oleh empat wilayah kabupaten diantaranya : 
- Kabupaten Probolinggo

- Kabupaten Pasuruan

- Kabupaten Lumajang

- Kabupaten Malang.

\section{Data dan Peralatan}

- Data

Data yang digunakan dalam penelitian ini meliputi :

1. Lima citra satelit Sentinel-1A menggunakan band- $C$ single polaritation (VV) dengan panjang gelombang $5,6 \mathrm{~cm}$.

2. Data Precise Orbit Ephemeride [AUX_PEORB].

3. DEM SRTM 30 meter.

Tabel 1. Data Citra Sentinel-1A

\begin{tabular}{|c|c|c|c|c|}
\hline No. & ID_Scene & Tanggal & Level & Arah \\
\hline 1. & $\begin{array}{l}\text { S1A_IW_SLC_1SSV } \\
\text { 20151109T104927_20 } \\
\text { 151109T104957_0085 } \\
\text { 26_00C12B_05D0 }\end{array}$ & $\begin{array}{l}\text { 9-November- } \\
2015\end{array}$ & $\begin{array}{l}1,0 \quad \text { (Single } \\
\text { Look } \\
\text { Complex })\end{array}$ & Ascending \\
\hline 2. & $\begin{array}{l}\text { S1A_IW_SLC_1SSV_} \\
\text { 20151227T104920_20 } \\
\text { 151227T104950_0092 } \\
\text { 26_00D4DA_0945 }\end{array}$ & $\begin{array}{l}\text { 27-Desember- } \\
2015\end{array}$ & $\begin{array}{l}1,0 \text { (Single } \\
\text { Look } \\
\text { Complex) }\end{array}$ & Ascending \\
\hline 3. & $\begin{array}{l}\text { S1A_IW_SLC_1SSV_ } \\
\text { 20160120T104920_20 } \\
\text { 160120T104949_0095 } \\
\text { 76_00DEE0_CBB5 }\end{array}$ & 20-Januari-2016 & $\begin{array}{l}1,0 \text { (Single } \\
\text { Look } \\
\text { Complex) }\end{array}$ & Ascending \\
\hline 4. & $\begin{array}{l}\text { S1A_IW_SLC_1SSV_ } \\
\text { 20160213T104919_20 } \\
\text { 160213T104949_0099 } \\
\text { 26_00E916_A92F }\end{array}$ & $\begin{array}{l}\text { 13-Februari- } \\
2016\end{array}$ & $\begin{array}{l}1,0 \quad \text { (Single } \\
\text { Look } \\
\text { Complex })\end{array}$ & Ascending \\
\hline 5. & $\begin{array}{l}\text { S1A_IW_SLC_1SSV } \\
\text { 20160308T104919_20 } \\
\text { 160308T104949_0102 } \\
\text { 76_00F325_F3D3 }\end{array}$ & 8-Maret-2016 & $\begin{array}{l}1,0 \text { (Single } \\
\text { Look } \\
\text { Complex) }\end{array}$ & Ascending \\
\hline
\end{tabular}

- Peralatan

Peralatan yang digunakan dalam penelitian ini meliputi Sistem Operasi Ubuntu 16.04 LTS, Sistem Operasi Windows 7, GMT 5, GMT-SAR.

\section{Pengolahan Data}

Berikut adalah penjelasan tahapan-tahapan pengolahan data SAR dengan teknologi DInSAR pada flowchart gambar 2, sebagai berikut :

1. Interferometry SAR Processing

Tujuan dari proses ini yaitu pembentukan citra interferogram dari sepasang data SLC yang terdiri dari citra master dan citra slave. Metode two pass terbentuk empat pasang citra.

2. Differential Interferometry SAR (DInSAR) Processing

Pada citra interferogram yang telah terbentuk dilakukan proses image filtering dengan menaikkan nilai Signal Noise Ratio (SNR) serta penghapusan efek topografi dengan menggunakan DEM SRTM 30 meter pada sistem koordinat radar.

3. Nilai Koherensi

Hasil dari proses DInSAR memiliki nilai koherensi dengan rentang nilai dari 0-1. Dimana jika nilai koherensi $=1$ menunjukkan bahwa citra master dan slave pada interferogram benarbenar identik, begitu pula sebaliknya dengan nilai koherensi $=0$. Pada penelitian ini menggunakan nilai koherensi 0,2 .

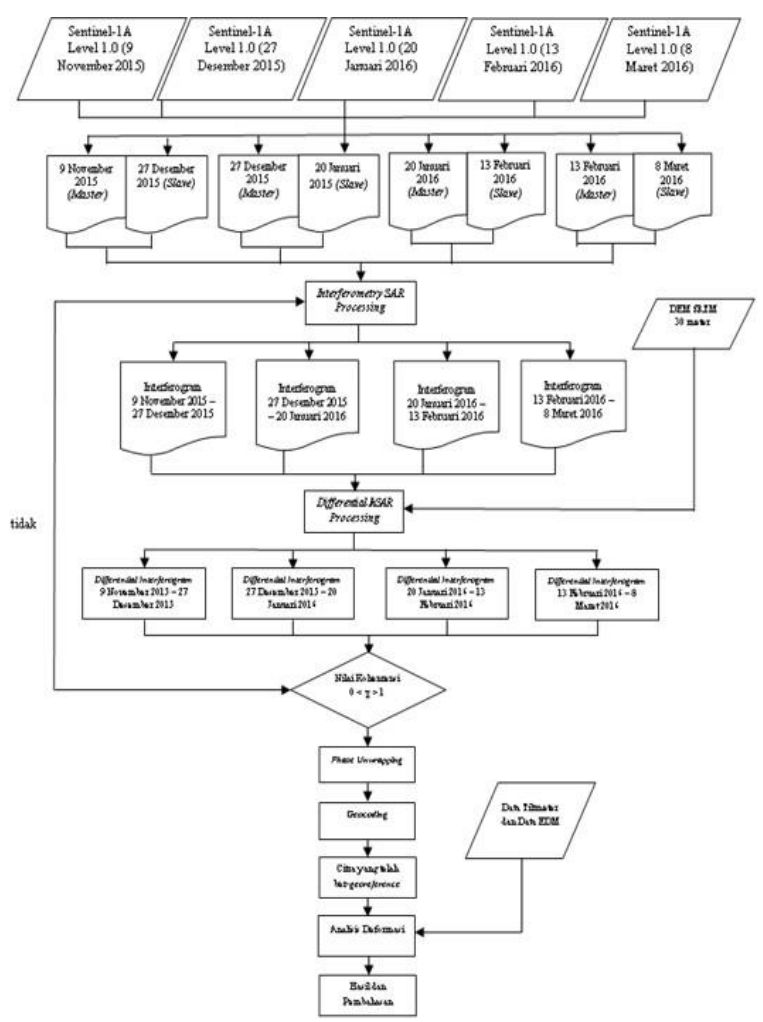

Gambar 2. Diagram Alir Pengolahan Data SAR Metode Two-Pass Interferometry

4. Phase Unwrapping dan Geocoding

Citra dari proses DInSAR masih dalam satuan radian (phase) dalam rentang $-\pi$ sampai dengan $\pi$, sehingga menimbulkan masalah ambiguitas. Pola deformasi sudah dapat terlihat tetapi informasi deformasi belum dapat terbaca dengan baik, sehingga dibutuhkan proses phase unwrapping untuk mendapatkan nilai phase absolut dan merubah satuan phase dari radian menjadi metrik. Sedangkan proses geocoding untuk melakukan transformasi koordinat kembali ke geografis.

5. Analisa Deformasi

Tahap analisa ini bertujuan untuk mengetahui terjadi deformasi pada hasil pengolahan SAR 
dan membandingkan besar deformasi pada permukaan gunung dari pengolahan yang dilakukan dengan data Tiltmeter dan data EDM.

\section{HASIL DAN PEMBAHASAN}

\section{Panjang Baseline dan Interval Waktu}

Dari data SLC yang digunakan dalam pemrosesan SAR dengan GMT-SAR diperoleh panjang baseline perpendicular dan jarak temporal pada tabel 2 .

Dapat dilihat pada tabel 2 bahwa dari tiga pasangan citra yang dibentuk interferogram memiliki panjang baseline perpendicular sebesar $-137,370996$ meter (pasangan citra 9 November 2015 - 27 Desember 2015), 77,881014 meter (pasangan citra 27 Desember 2015 - 20 Januari 2016), 10,034544 meter (pasangan citra 20 Januari 2016 - 13 Februari 2016), -54,591658 meter (pasangan citra 13 Februari 2016 - 8 Maret 2016).

Tabel 2. Baseline Perpendicular dan Jarak Temporal

\begin{tabular}{|c|c|c|c|}
\hline ID_Scene & Tanggal & $\begin{array}{c}\text { Baseline } \\
\text { Perpendicular }\end{array}$ & $\begin{array}{l}\text { Baseline } \\
\text { Temporal }\end{array}$ \\
\hline S1A_IW_SLC & & \multirow{5}{*}{$\begin{array}{l}-137,370996 \\
\text { meter }\end{array}$} & \multirow{5}{*}{47 hari } \\
\hline _20151109T & 9 November & & \\
\hline 104927_201 & $2015-27$ & & \\
\hline 51227T1049 & Desember 2015 & & \\
\hline 20 & & & \\
\hline S1A_IW_SLC & & \multirow{5}{*}{$\begin{array}{c}77,881014 \\
\text { meter }\end{array}$} & \multirow{5}{*}{24 hari } \\
\hline _20151227T & 27 Desember & & \\
\hline 104920_201 & $2015-20$ & & \\
\hline 60120T1049 & Januari 2016 & & \\
\hline 20 & & & \\
\hline S1A_IW_SLC & & \multirow{5}{*}{$\begin{array}{c}10,034544 \\
\text { meter }\end{array}$} & \multirow{5}{*}{24 hari } \\
\hline _20160120T & 20 Januari 2016 & & \\
\hline 104920- & -13 Februari & & \\
\hline _20160213T & 2016 & & \\
\hline 104919 & & & \\
\hline S1A_IW_SLC & & \multirow{5}{*}{$\begin{array}{c}-54,591658 \\
\text { meter }\end{array}$} & \multirow{5}{*}{24 hari } \\
\hline _20160213T & 13 Februari & & \\
\hline 104919_201 & 2016-8 Maret & & \\
\hline $60308 T 1049$ & 2016 & & \\
\hline 19 & & & \\
\hline
\end{tabular}

Semakin panjang nilai baseline perpendicular maka tingkat koherensi citra akan terus menurun dikarenakan semakin jauhnya perbedaan posisi orbit satelit ketika melakukan pengambilan citra. Begitu juga dengan besarnya nilai baseline temporal yang jika nilainya semakin besar akan menyebabkan temporal decorelation dan berhubungan dengan besarnyanilai koherensi pada citra interferogram.

Koherensi citra yang rendah juga mengakibatkan karakteristik objek dari kedua sisi juga berbeda dan adanya perubahan pada objek yang diamati (Sari 2014).

\section{Analisa Besar Deformasi Area Studi}

Pada scale bar yang ditunjukkan pada gambar 3,4 , 5, dan 6, warna merah pada citra menunjukkan terjadinya kenaikan permukaan tanah (inflasi) pada permukaan Gunung Bromo. Sedangkan warna biru menunjukkan terjadinya penurunan permukaan tanah (deflasi). Warna putih pada scale bar menunjukkan area pada studi kasus yang hampir atau tidak mengalami inflasi atau deflasi. Pada gambar 3, menunjukkan wilayah sekitar kaldera sebagian besar mengalami deflasi pada nilai antara $0 \mathrm{~mm} \mathrm{~s} / \mathrm{d}-20 \mathrm{~mm}$. Pada gambar 4, menunjukkan wilayah sekitar kaldera sebagian besar mengalami deflasi pada nilai antara $-20 \mathrm{~mm} \mathrm{~s} / \mathrm{d}-60 \mathrm{~mm}$. Pada gambar 5, menunjukkan wilayah sekitar kaldera sebagian besar mengalami inflasi pada nilai antara $0 \mathrm{~mm} \mathrm{~s} / \mathrm{d} 30 \mathrm{~mm}$. Pada gambar 6, menunjukkan wilayah sekitar kaldera sebagian besar mengalami inflasi pada nilai antara $0 \mathrm{~mm} \mathrm{~s} / \mathrm{d} 40 \mathrm{~mm}$. Berdasarkan gambar 3, 4, 5, dan 6, terjadi perubahan pada permukaan badan gunung berupa penurunan dan kenaikan sebelum dan sesudah terjadinya aktivitas erupsi.

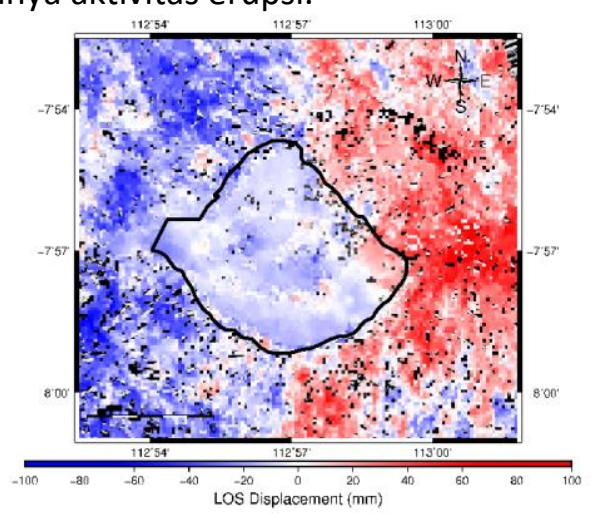

Gambar 3. Nilai LOS Displacement 9 November 2015 27 Desember 2015

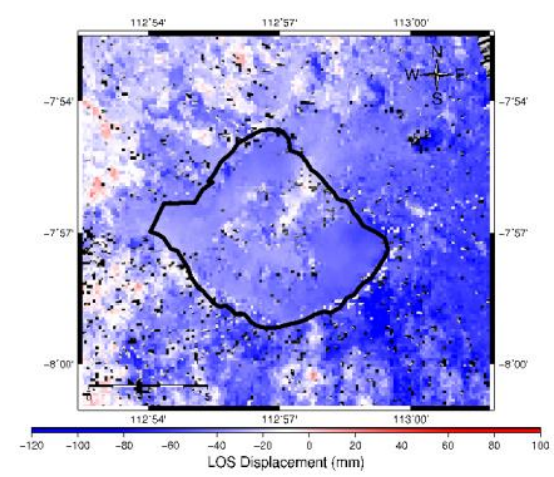

Gambar 4. Nilai LOS Displacement 27 Desember 2015 20 Januari 2016 


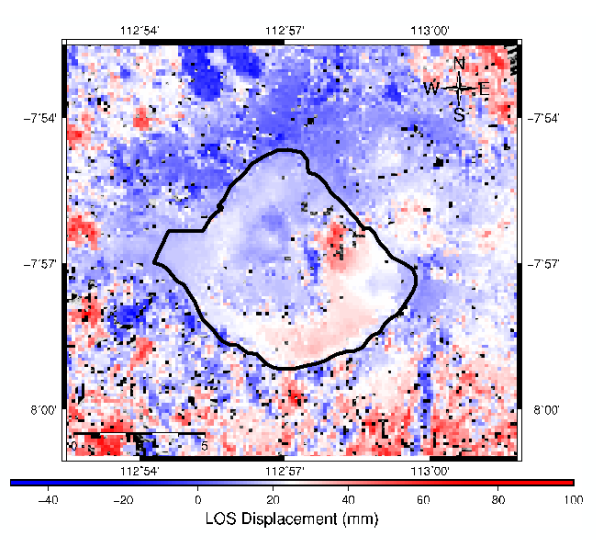

Gambar 5. Nilai LOS Displacement 20 Januari 2016 13 Februari 2016

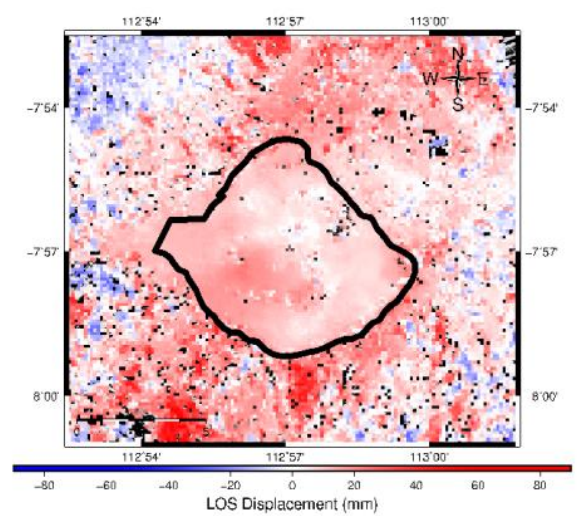

Gambar 6. Nilai LOS Displacement 13 Februari 2016 8 Maret 2016

\section{KESIMPULAN}

Berdasarkan pengolahan dan analisis data yang telah dilakukan, berikut adalah kesimpulan yang penulis dapatkan dalam penelitian ini:

1. Metode two pass pada teknologi DInSAR dapat merefleksikan peningkatan aktivitas di Gunung Bromo untuk mengetahui besar nilai deformasi di wilayah permukaan Gunung Bromo khususnya di sekitar kaldera dengan ketelitian sub-milimeter.

2. Berdasarkan hasil pengolahan DInSAR, besar deformasi berdasarkan LOS diplacement pada 9 November 2015 - 27 Desember 2015 sebesar $0 \mathrm{~mm} \mathrm{~s} / \mathrm{d}-20 \mathrm{~mm}, 27$ Desember 2015 - 20 Januari 2016 sebasar $-20 \mathrm{~mm} \mathrm{~s} / \mathrm{d}$ $60 \mathrm{~mm}, 20$ Januari 2016 - 13 Februari 2016 sebesar $0 \mathrm{~mm}$ s/d $30 \mathrm{~mm}, 13$ Februari 2016 - 8 Maret 2016 sebesar $0 \mathrm{~mm} \mathrm{~s} / \mathrm{d} 40 \mathrm{~mm}$.

\section{UCAPAN TERIMA KASIH}

Penulis I.V.A. mengucapkan terima kasih kepada PVMBG yang telah menyediakan data untuk keperluan penelitian, Bapak Dr.Ir. Muhammad Taufik dan Ibu Ira Mutiara Anjasmara, S.T, M.Phil, Ph.D selaku dosen pembimbing yang telah memberikan dukungan dan bimbingan selama penelitian dilaksanakan.

\section{DAFTAR PUSTAKA}

Y. Wismaya, I. Anjasmara. 2016. Analisis Deformasi Gunung Merapi Berdasarkan Data Pengamatan GPS Februari-Juli 2015. Surabaya: Teknik Geomatika ITS.

I. Pratomo. 2006. Klasifikasi Gunung Api Aktif Indonesia Studi Kasus dari Beberapa Letusan Gunung Api Dalam Sejarah. Jurnal Indonesian Journal on Geoscience, Vol. 1 No. 4, 209-227.

Chang-Wook, L., Zhong, L., Hyung-Sup, J., dan Oh-lg, K. 2008. "Surface Displacements of The St. Augustine Volcano, Alaska, Measured From an DInSAR and GPS Data". 7th European Conference Synthetic Aperture Radar (EUSAR).

Rivera, A., Amelung, F., dan Eco, R. 2016. "Volcano Deformation and Modeling on Active Volcanoes in The Philippines From Alos Insar Time Series". Geochemistry Geophysics Geosystems 17(7).

Hanssen, R. 2001. Radar Interferometry: Data Interpretation and Error Analysis Vol. 2. Springer.

Yudha, E., Mulyo , B., Yuwono, dan Wiweka. 2011. "Studi Deformasi Gunung Merapi Menggunakan Teknologi Interferometry Synthetic Aperture Radar (InSAR)". Digilib ITS.

Sari, A. 2014. Metode Differential Interferometry Synthetic Aparture Radar (DINSAR) untuk Analisa Deformasi Di Daerah Rawan Bencana Gempa Bumi (Studi Kasus : Kepulauan Mentawai, Sumatera Barat). Surabaya: Jurusan Teknik Geomatika Institut Teknologi Sepuluh Nopember.

Tamm, T., Zalite, K., Voormansik, K., dan Talgre, L. 2016. "Relating Sentinel-1 Interferometric Coherence to Mowing Events on Grasslands". Remote Sensing. 